\title{
Thermal Expansion Behaviour of Ternary Nickel-Based, Cobalt-Based, and Iron-Based Alloys Containing Very High Fractions of Carbides
}

\author{
Patrice Berthod and Lionel Aranda \\ Team 206 "Surface and Interface, Chemical Reactivity of Materials", Department of Chemistry and Physics of Solids and Surface, \\ Institut Jean Lamour (UMR CNRS 7198), Faculty of Sciences and Technologies, University of Lorraine, Boulevard des Aiguillettes, \\ BP 70239, 54506 Vandoeuvre-lès-Nancy, France \\ Correspondence should be addressed to Patrice Berthod, patrice.berthod@ijl.nancy-universite.fr
}

Received 27 August 2012; Accepted 13 September 2012

Academic Editors: F. Hori and M.-C. Wang

Copyright ( $\odot 2012$ P. Berthod and L. Aranda. This is an open access article distributed under the Creative Commons Attribution License, which permits unrestricted use, distribution, and reproduction in any medium, provided the original work is properly cited.

\begin{abstract}
Some of the wear-resistant pieces or coatings, constituted of a metallic matrix and of carbides present in high fractions, are a mix, in similar quantities, of two materials displaying greatly different levels of hardness but also of thermal expansion coefficient. When temperature increases, the second difference of property may lead to particular geometrical behaviours. To study these differences, nine nickel-based, cobalt-based, and iron-based alloys containing very high quantities of carbides were elaborated by foundry. In their as-cast conditions, the microstructures of these alloys were characterized; their hardness and thermal expansion until $1200^{\circ} \mathrm{C}$ were measured and analysed, with regard to the evolution of the structures predicted by thermodynamic calculations. The hardness of the alloys is high (nickel alloys) or very high (cobalt and iron alloys, $600 \mathrm{Hv}$ and more) while the thermal expansion is greatly influenced by carbides, notably when temperature has become very high. Some of the variations of thickness at the end of heating or during an isothermal stage at $1200^{\circ} \mathrm{C}$, essentially contraction, directly result from the mechanical interaction between matrix and carbides which was accumulated during the heating.
\end{abstract}

\section{Introduction}

Refractory metallic alloys containing significant quantities of carbides are of a great importance for high temperature applications $[1,2]$, even if they are less common than the $\gamma / \gamma^{\prime}$-type superalloys, solid-solution strengthened cobaltbased superalloys, or heat-resistant steels. Many of the carbides-strengthened alloys are based on nickel, cobalt, or iron and elaborated by foundry. They generally contain great quantities (several tens percents in weight) of chromium, which is a carbide-former element promoting, in presence of carbon, the formation of $\mathrm{Cr}_{7} \mathrm{C}_{3}$ or $\mathrm{Cr}_{23} \mathrm{C}_{6}$ carbides.

The chromium-rich cast nickel-based alloys are used for numerous applications, notably for turbine blades in aeronautics, for which chromium brings to the alloys a good resistance against high temperature oxidation [3, 4]. Carbon can be added to the (Ni, Cr-) based alloys in order to obtain high levels of mechanical resistance and an example of hardness [5-8]. Cobalt-based alloys rich in chromium are also considered for hot parts in aeronautic turbines and power generation machines, as well as for other applications like some of the fiberizing tools used in the glass industry [9]. Generally several tens of weight percents of chromium are added to cobalt to allow the alloy sufficiently resisting hot corrosion by various molten substances (salts, glasses, etc.), as well as high temperature oxidation. Its role can be also to develop carbides with carbon for improving the high temperature mechanical resistance against creep. High levels of hardness can be expected but they are generally achieved using other types of carbides, as for cutting tools [10], made of a cobalt matrix containing high amounts of dispersed WC carbides, or for coatings [5] consisting in Co- $\mathrm{W}_{2} \mathrm{C}$ deposited by thermal spray on steels. It is well known that the carbon-containing iron-based alloys are able to offer great 
volume fractions of hard phases (as cementite, pearlite, or martensite) which allow leading to high hardness values. In their cases too, chromium can be added to the chemical composition to enhance mechanical resistance or hardness of bulks [11] or of hardfacing coatings [12] by forming numerous interdendritic chromium carbides.

Thus, chromium carbides can be met in nickel-, cobaltor iron-based alloys to mechanically strengthen them at high temperature (moderate amounts of carbon and fractions of carbides) or for wear-resistance purpose (high-carbon contents and carbides fractions). In all cases, in service, the temperature of such alloys can increase up to high levels (several hundreds of Celsius degrees), either because of a high temperature in use (e.g., superalloy in turbine blades exposed to hot gases, near $1000-1300^{\circ} \mathrm{C}$ ) or because of a heating due to friction/abrasion (e.g., cutting tool, lower temperatures). The difference of thermal expansion coefficient existing between matrix $\left(15-20 \times 10^{-6 \circ} \mathrm{C}^{-1}\right)$ and carbides $(10 \times$ $\left.10^{-6 \circ} \mathrm{C}^{-1}\right)[13]$ may then induce a particular global thermal expansion behaviour for the whole alloy.

The aim of this work is to study the possible matrixcarbides mechanical interactions during heating and cooling and their consequences on the thermal expansion behaviours of several model nickel-based alloys, cobalt-based alloys, and iron-based alloys, all containing the same high quantity of chromium and, for each family, three different high levels in carbon to obtain three different high carbide fractions.

\section{Details of the Experiments}

2.1. Elaboration of the Studied Alloys. Nine high-carbon $30 \mathrm{wt}$ \% Cr-containing ternary alloys were synthesized by foundry from pure elements. They are M-30Cr- $x \mathrm{C}$ alloys, with $\mathrm{M}=\mathrm{Ni}$, Co or $\mathrm{Fe}$, and $x=2.5,3.0$ or $3.5 \mathrm{wt} . \%$. The ingots, of a mass equal to about $30 \mathrm{~g}$, were cast in the watercooled copper crucible of a High Frequency induction furnace (CELES), under an inert atmosphere of 300 millibars of pure argon, by melting pure elements together (purity higher than $99 \%$ in mass): $\mathrm{Co}, \mathrm{Ni}, \mathrm{Fe}$, and $\mathrm{Cr}$ coming from Alfa Aesar, and $\mathrm{C}$ added as pure graphite.

2.2. Metallographic Preparation and Characterization: Hardness Measurements. The ingots were thereafter cut using a Buehler Isomet 5000 precision saw. A sample per ingot was embedded in a cold resin (Escil CY230 + HY956), and the mounted samples were polished by using SiC paper from 120 to 1200 grit under water, then with a $1 \mu \mathrm{m}$-diamond paste. A Philips XL30 Scanning Electron Microscope was used for metallographic observations, essentially in the Back Scattered Electrons mode (BSE) under an acceleration voltage of $20 \mathrm{kV}$. The chemical composition of each alloy was controlled in the bulk, by using a Cameca SX microprobe in a delocalized mode (magnification: $\times 400$ ) on several locations, while a Philips XPERT'Pro diffractometer was also used to complete the metallographic characterization.

The hardness of each mounted and polished alloy was measured by performing Vickers indentations under a $30 \mathrm{~kg}$ load, using a Testwell Wolpert device.
2.3. Dilatometry Runs and Thermodynamic Calculations. The thermal expansion was measured using a TMA 92-16.18 Setaram apparatus on parallelepipedic samples cut in each ingot the dimensions of which were about $4 \mathrm{~mm} \times 4 \mathrm{~mm}$ (square main faces) $\times 2 \mathrm{~mm}$ (direction of the characterized expansion). The heating was performed from ambient tem-

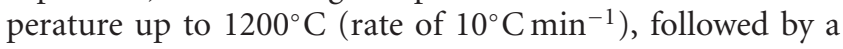
dwell of 1 hour and then a cooling down to ambient temperature (rate of $-10^{\circ} \mathrm{C} \mathrm{min}^{-1}$ ). Three parts of the evolution of the sample's thickness were studied: the thermal expansion during the heating, the thermal contraction during the cooling, and the isothermal dimensional evolution during the 1 -hour dwell at $1200^{\circ} \mathrm{C}$.

In order to interpret the phenomena occurring during the dilatometry runs calculations of thermodynamic, stable states were carried out using the Thermo-Calc software [14] and a data base containing the descriptions of the $\mathrm{Cr}-\mathrm{C}$ system [15], of the Ni-C, Ni-Cr and Ni-Cr-C [16-18] systems for the nickel alloys, of the $\mathrm{Co}-\mathrm{C}, \mathrm{Co}-\mathrm{Cr}$, and $\mathrm{Co}-\mathrm{Cr}-\mathrm{C}$ systems for the cobalt alloys [15, 17-19], and of the Fe-C, $\mathrm{Fe}-\mathrm{Cr}$, and $\mathrm{Fe}-\mathrm{Cr}-\mathrm{C}$ systems [20-23] for the iron alloys.

\section{Results}

3.1. Microstructures and Room Temperature Hardness of the Alloys. All the alloys in the as-cast conditions were examined using the Scanning Electron Microscope (SEM) in Back Scattered Electrons (BSE) mode. Nine micrographs illustrating their microstructures are given in Figure 1.

The three as-cast nickel alloys display microstructures constituted in both matrix and carbides. In all cases, the alloy's matrix is a nickel-FCC solid solution, and the carbides are both $\mathrm{Cr}_{7} \mathrm{C}_{3}$ and $\mathrm{Cr}_{3} \mathrm{C}_{2}$, as revealed by X-ray diffraction. This can be also seen on the BSE micrographs with the coarse proeutectic carbides; the outer part of which is darker than the middle (the $\mathrm{Cr}_{7} \mathrm{C}_{3}$ carbides were seemingly transforming into $\mathrm{C}$-richer $\mathrm{Cr}_{3} \mathrm{C}_{2}$ carbides during cooling). All microstructures are effectively of a hypereutectic type, with presence of these acicular proeutectic carbides, which are discrete in the $\mathrm{Ni}-30 \mathrm{Cr}-2.5 \mathrm{C}$ alloy but which become more present and coarse for the two highest carbon contents, 3.0 and $3.5 \mathrm{wt} . \%$. The hardness values increase with the carbon content, from $341 \pm 10$ for $2.5 \mathrm{C}$ to $386 \pm 15$ for $3.5 \mathrm{C}$ $\left(\mathrm{Hv}_{30 \mathrm{~kg}}\right)$.

For the three as-cast cobalt alloys, the microstructure are, on the contrary, hypoeutectic for $2.5 \mathrm{C}$ and $3.0 \mathrm{C}$ and seemingly eutectic for 3.5C. The matrix is a mix of HCP and FCC cobalt solid solutions and carbides are essentially $\mathrm{Cr}_{7} \mathrm{C}_{3}$. These alloys are significantly harder than the nickel alloys since their hardness increase from $588 \pm 15$ for $2.5 \mathrm{C}$ to $646 \pm$ 10 for $3.5 \mathrm{C}\left(\mathrm{Hv}_{30 \mathrm{~kg}}\right)$.

With the three iron-based alloys, the three microstructures characters, hypoeutectic, eutectic and hypereutectic, are represented with the $\mathrm{Fe}-30 \mathrm{Cr}-2.5 \mathrm{C}, \mathrm{Fe}-30 \mathrm{Cr}-3.0 \mathrm{C}$, and $\mathrm{Fe}-$ 30Cr-3.5C alloys, respectively. As shown by X-ray diffraction, the matrix is Centred Cubic, and the carbides are $\mathrm{Cr}_{7} \mathrm{C}_{3}$ in all cases. The hardness increases from $584 \pm 4$ for $2.5 \mathrm{C}$ to $619 \pm$ 12 for $3.5 \mathrm{C}\left(\mathrm{Hv}_{30 \mathrm{~kg}}\right)$. 


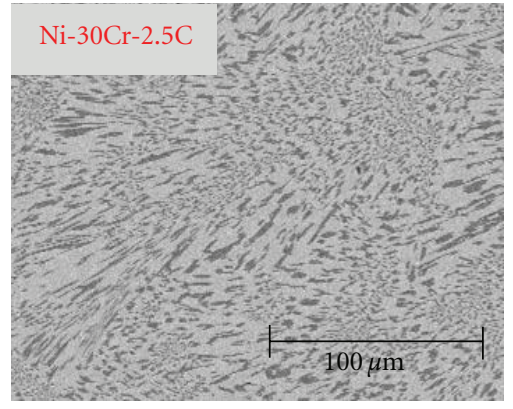

(a)

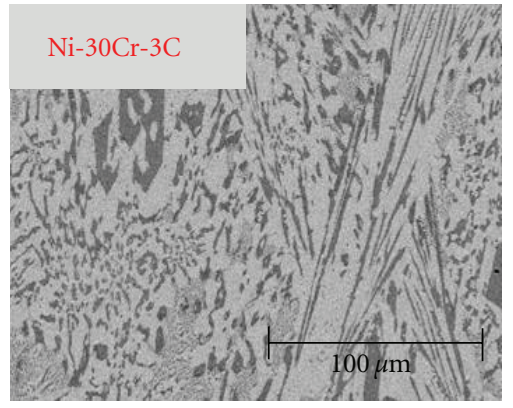

(d)

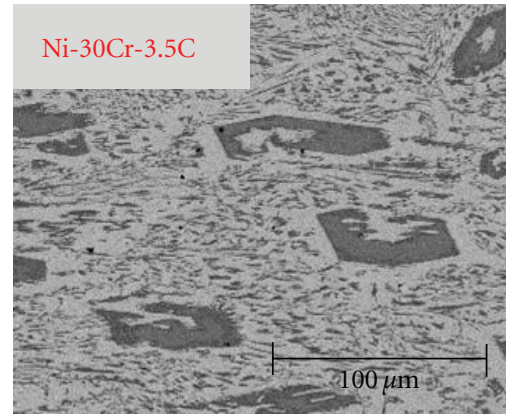

(g)

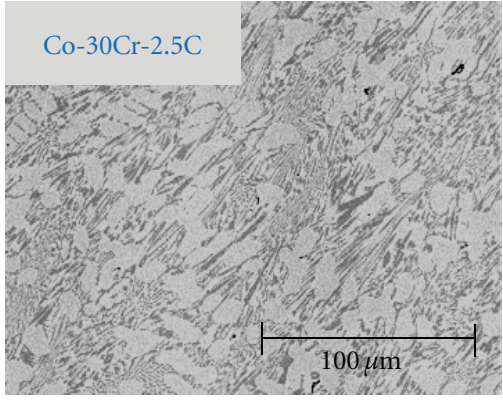

(b)

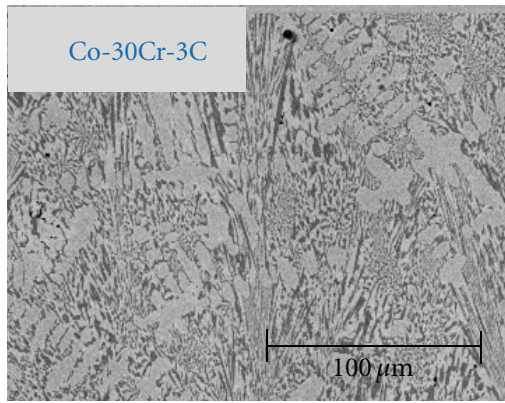

(e)

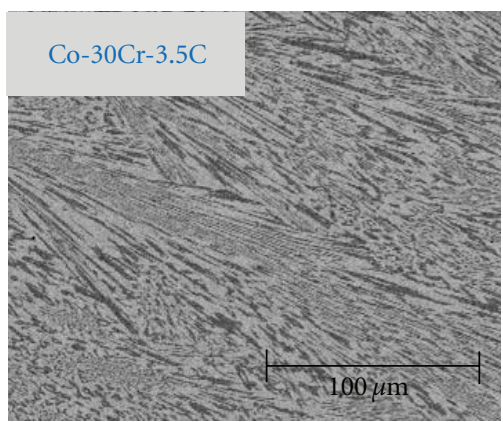

(h)

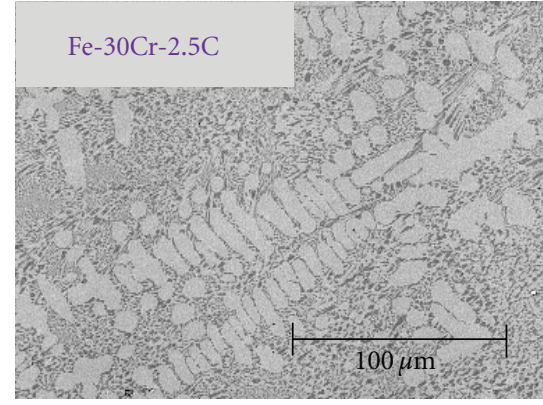

(c)

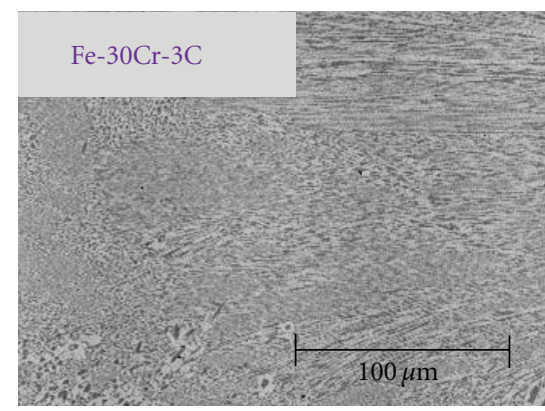

(f)

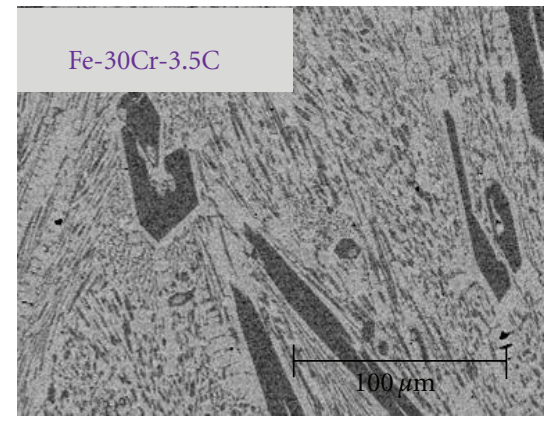

(i)

Figure 1: Microstructures of the studied alloys (SEM/BSE micrographs).

3.2. Thermal Expansion Behaviours. The obtained dilatometry curves are given in Figure 2 for the nickel alloys, Figure 3 for the cobalt alloys, and Figure 4 for the iron alloys. Only their parts above $100^{\circ} \mathrm{C}$ (and even sometimes $200^{\circ} \mathrm{C}$ ) were taken under consideration because perturbations caused at very low temperature by the thermal equilibrium establishment of the apparatus.

The thermal expansion of the nickel alloys (Figure 2) is often almost linear from $100^{\circ} \mathrm{C}$ to $1200^{\circ} \mathrm{C}$, with a thermal expansion coefficient of around $17-18 \times 10^{-6 \circ} \mathrm{C}^{-1}$. However, when approaching the maximal temperature, one can notice a deceleration of expansion in the case of the Ni-30Cr-3.5C alloy, over about $900^{\circ} \mathrm{C}$. During the isothermal stage a contraction happens. It is revealed by a position of the $1200^{\circ} \mathrm{C}$ extremity of the heating part of the dilatometry curve which is higher than the $1200^{\circ} \mathrm{C}$-extremity of its cooling part (Figure 2, graphs on the left side). These contractions are more visible on the graphs presented in the right side of the same figure, with curves plotted versus time instead temperature. One can see an isothermal contraction initially rapid and slower thereafter, which is more pronounced for the highest carbon alloy than for the others: the absolute value of the total isothermal contraction increased from $0.09 \%$ to $0.24 \%$ (Table 1 ) for carbon content in the alloy increasing from 2.5 to $3.5 \mathrm{wt} . \% \mathrm{C}$. This generally results in a residual negative deformation after return at $100^{\circ} \mathrm{C}$, the absolute value of which increases from $0.04 \%$ to $0.18 \%$ for a carbon content in the alloy increasing from 2.5 to $3.5 \mathrm{wt} . \%$ C.

The cobalt alloys do not present so clear evolution of their thermal expansion behaviour versus the carbon content (Figure 3). Indeed, if the Co-30Cr-2.5C alloy behaves like the nickel alloy with the same carbon content, curious phenomena affect the thermal expansion curves of the two C-richest cobalt alloys. The Co-30Cr-3.0C curve suddenly jumps near $1000^{\circ} \mathrm{C}$ just before knowing a contraction (sudden too) when approaching $1200^{\circ} \mathrm{C}$. This contraction goes on during the stage over a particularly high amplitude $(-0.52 \%$, Table 2$)$. 

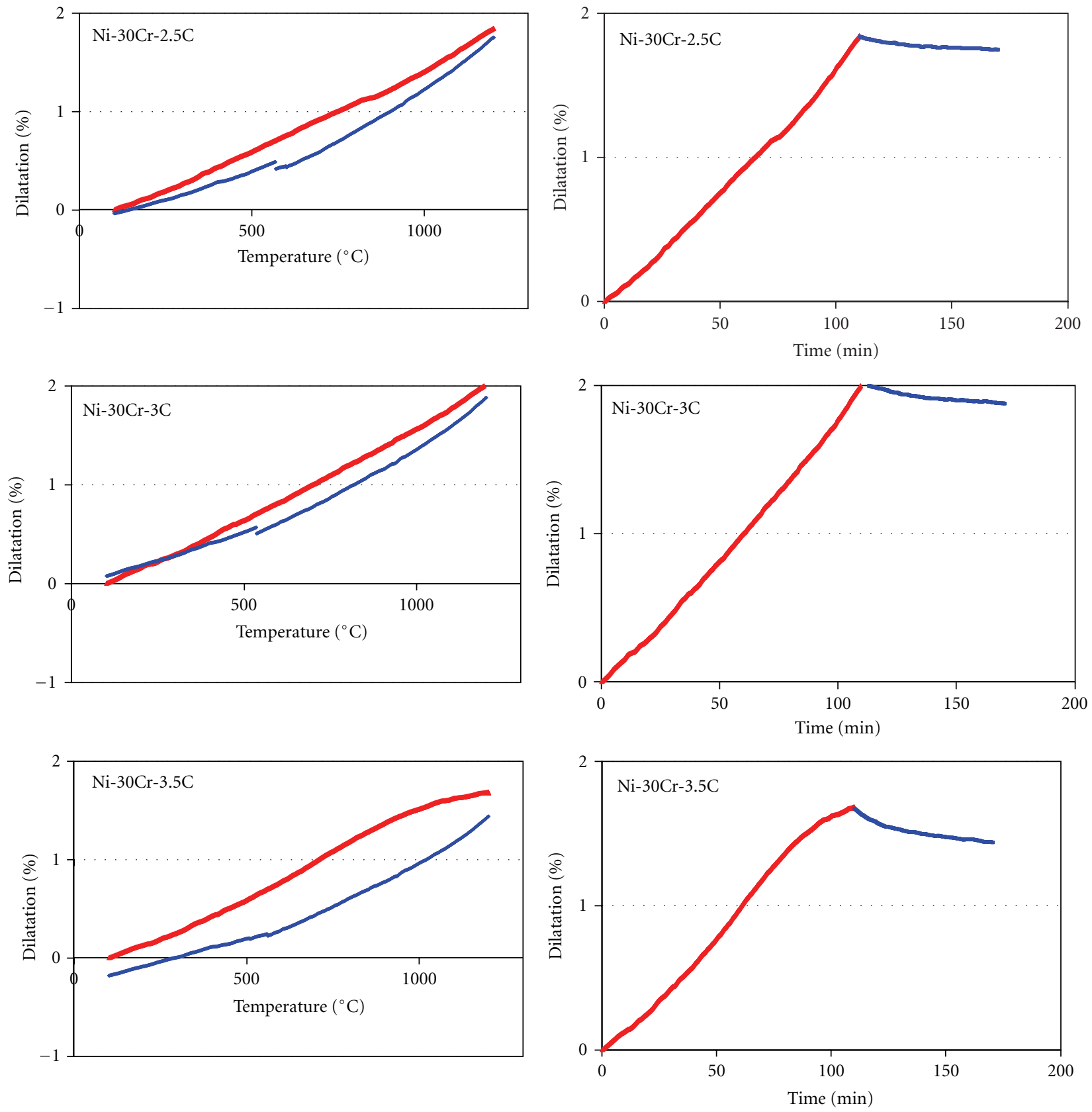

^ Heating

$\Delta$ Heating

- Cooling

- Dwell

(a)

(b)

Figure 2: The whole thermal expansion curves of the nickel-based alloys versus temperature (left) and the (heating + isothermal) parts versus time (right).

A similar phenomenon seems affecting the high temperature part of the heating dilatometry curve of the Co-30Cr-3.5C alloy, but with amplitudes much lower. The cooling part of all curves presents a small dilatation near $700^{\circ} \mathrm{C}$. Concerning the average thermal expansion coefficient (determined on the linear part of the heating dilatometry curve), it is of about 16 $\times 10^{-6 \circ} \mathrm{C}^{-1}$ for the three alloys, as is to say a little smaller than for the nickel alloys.
The iron alloys present dilatometry curves; the heating part of which can be divided into two parts. The average thermal coefficient (Table 3) on the low temperature part (typically $<800^{\circ} \mathrm{C}$ ) is generally lower than the one of the high temperature part $\left(>800^{\circ} \mathrm{C}\right.$ ), and these two $\alpha$ coefficients both decrease when the carbon content increases (from 18 to less than $16 \times 10^{-6{ }^{\circ}} \mathrm{C}^{-1}$ for the low temperature part, and from $25 \times 10^{-6 \circ} \mathrm{C}^{-1}$ to $14 \times 10^{-6{ }^{\circ}} \mathrm{C}^{-1}$ for the high 
TABLE 1: Thermal expansion coefficients measured on the dilatometry curves, deformation at $T$ reaching $1200^{\circ} \mathrm{C}$, deformation and total deformation values after the $1200^{\circ} \mathrm{C}$-isothermal stage $\left(\Delta \varepsilon_{1200 \%}\right)$ and after return to $100^{\circ} \mathrm{C}\left(\Delta \varepsilon_{100 \%}\right)$-nickel-based alloys.

\begin{tabular}{lccc}
\hline Temperature $\left({ }^{\circ} \mathrm{C}\right)$ & & Average linear thermal expansion coefficient $\left(\times 10^{-6 \circ} \mathrm{C}^{-1}\right)$ & Ni-30Cr-3.5C \\
\hline Average $\alpha\left(10^{-6} \mathrm{~K}^{-1}\right)$ & Ni-30Cr-2.5C & $\mathbf{1 8 . 2}$ & $\mathbf{1 7 . 8}$ \\
$T$ range for $\alpha$ & $100-1200^{\circ} \mathrm{C}$ & $100-1200^{\circ} \mathrm{C}$ & $100-900^{\circ} \mathrm{C}$ \\
$\varepsilon_{1200 \%}$ end heating & 1.843 & 2.012 & 1.674 \\
$\varepsilon_{1200 \%}$ start cooling & 1.751 & 1.881 & 1.439 \\
Total $\Delta \varepsilon_{120 \%}$ & -0.092 & -0.131 & -0.235 \\
Total $\Delta \varepsilon_{100 \%}$ & -0.035 & +0.077 & -0.180 \\
\hline
\end{tabular}
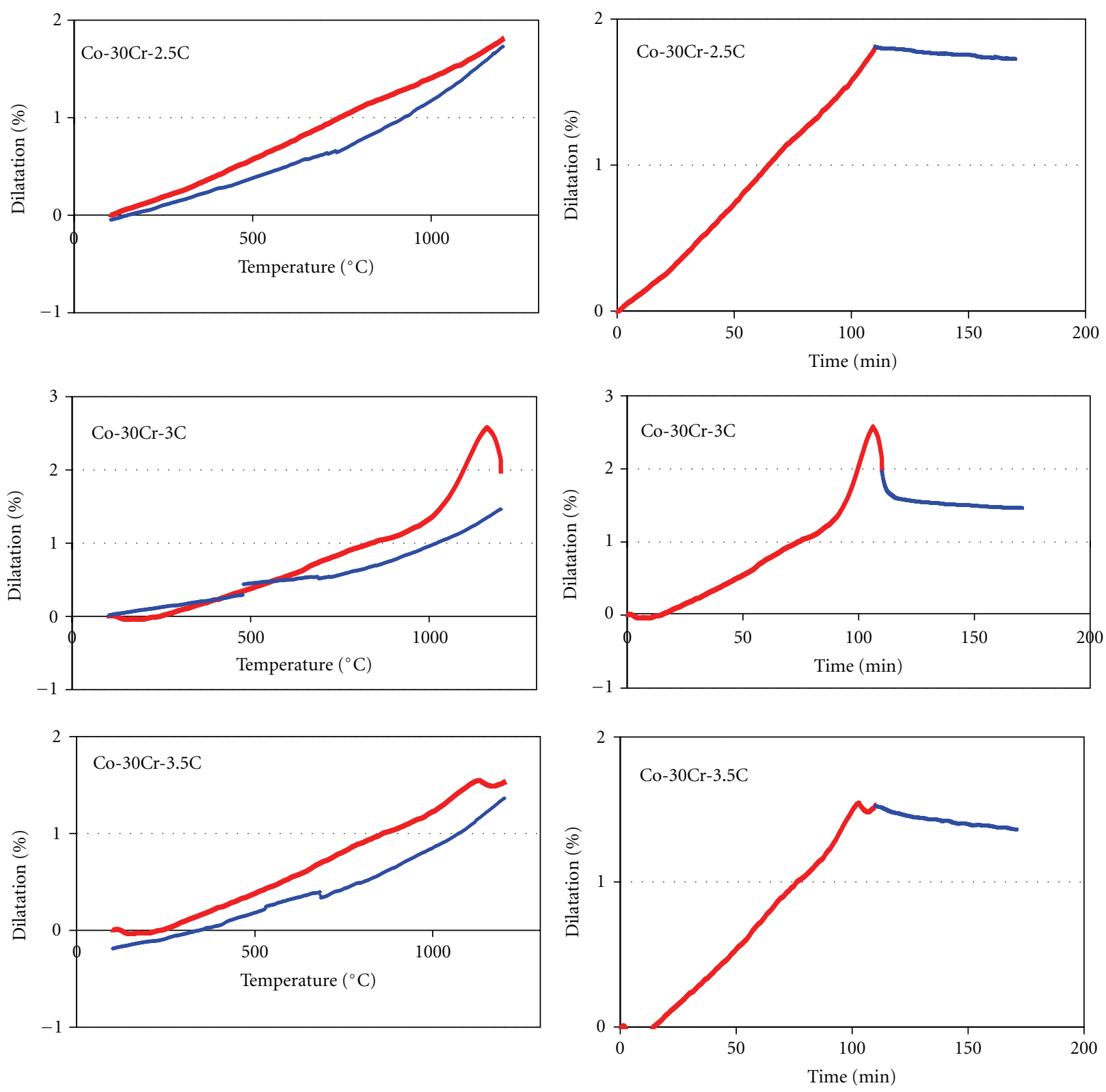

Heating
Cooling

${ }^{\Delta}$ Heating

-Dwell

(a)

(b)

Figure 3: The whole thermal expansion curves of the cobalt-based alloys versus temperature (left) and the (heating + isothermal) parts versus time (right). 

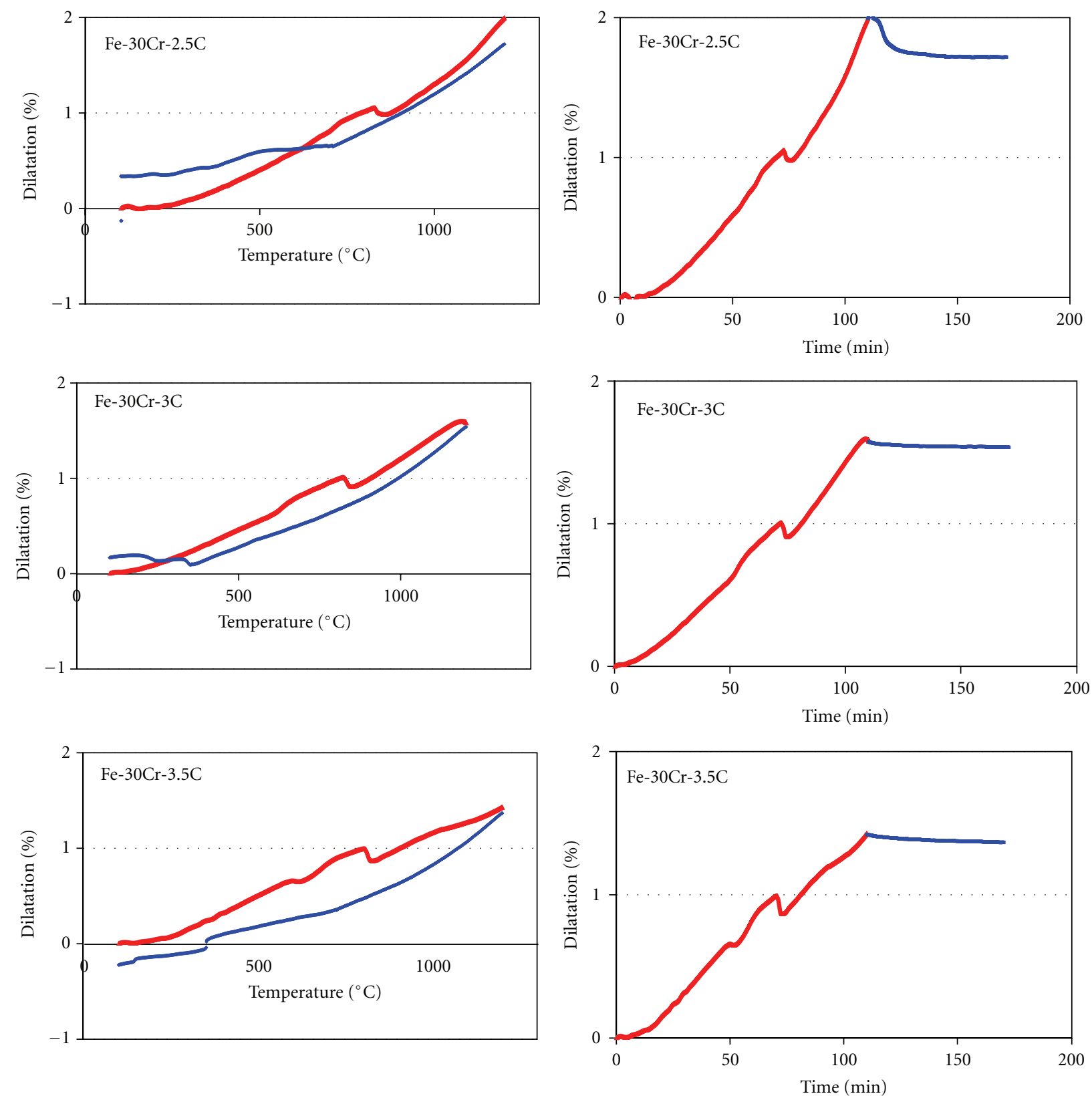

Heating
Cooling

A Heating

- Dwell

(a)

(b)

FIGURE 4: The whole thermal expansion curves of the iron-based alloys versus temperature (left) and the (heating + isothermal) parts versus time (right).

temperature part). At the end of heating and during the isothermal stage, there is also a contraction but which is curiously less pronounced when the carbon content of the alloy is higher, as is to say contrarily to what was observed for the nickel alloys. Indeed, the absolute value of the isothermal contraction decreases from 0.28 to $0.06 \%$ when the carbon content increases from 2.5 to $3.5 \mathrm{wt}$.\%. However, the residual deformation after return to $100^{\circ} \mathrm{C}$ after cooling decreases (from +0.34 to $-0.22 \%$ ) when the carbon content in the alloy increases, as observed for the nickel alloys and for the cobalt alloys.

\section{Discussion}

Thus, with such high carbon contents, the Ni-30Cr, Co$30 \mathrm{Cr}$, and $\mathrm{Fe}-30 \mathrm{Cr}$ systems present high densities of carbides, $\mathrm{Cr}_{7} \mathrm{C}_{3}$ exclusively (cases of the cobalt or iron alloys) or together with the $\mathrm{C}$-richer $\mathrm{Cr}_{3} \mathrm{C}_{2}$ carbides for the nickel 
TABle 2: Thermal expansion coefficients measured on the dilatometry curves, deformation at $T$ reaching $1200^{\circ} \mathrm{C}$, deformation and total deformation values after the $1200^{\circ} \mathrm{C}$-isothermal stage $\left(\Delta \varepsilon_{1200 \%}\right)$ and after return to $100^{\circ} \mathrm{C}\left(\Delta \varepsilon_{100 \%}\right)$ - cobalt-based alloys.

\begin{tabular}{|c|c|c|c|}
\hline \multirow{2}{*}{ Temperature $\left({ }^{\circ} \mathrm{C}\right)$} & \multicolumn{3}{|c|}{ Average linear thermal expansion coefficient $\left(\times 10^{-6 \circ} \mathrm{C}^{-1}\right)$} \\
\hline & Co-30Cr-2.5C & Co-30Cr-3.0C & Co-30Cr-3.5C \\
\hline Average $\alpha\left(10^{-6} \mathrm{~K}^{-1}\right)$ & 16.5 & 15.8 & 16.1 \\
\hline$T$ range for $\alpha$ & $100-1200^{\circ} \mathrm{C}$ & $200-900^{\circ} \mathrm{C}$ & $200-1000^{\circ} \mathrm{C}$ \\
\hline$\varepsilon_{1200 \%}$ end heating & 1.812 & 1.977 & 1.527 \\
\hline$\varepsilon_{1200 \%}$ start cooling & 1.728 & 1.462 & 1.363 \\
\hline Total $\Delta \varepsilon_{1200 \%}$ & -0.084 & -0.515 & -0.164 \\
\hline Total $\Delta \varepsilon_{100 \%}$ & -0.049 & +0.013 & -0.190 \\
\hline
\end{tabular}

TABle 3: Thermal expansion coefficients measured on the dilatometry curves, deformation at $T$ reaching $1200^{\circ} \mathrm{C}$, deformation and total deformation values after the $1200^{\circ} \mathrm{C}$-isothermal stage $\left(\Delta \varepsilon_{1200 \%}\right)$ and after return to $100^{\circ} \mathrm{C}\left(\Delta \varepsilon_{100 \%}\right)$-iron-based alloys.

\begin{tabular}{lccc}
\hline Temperature $\left({ }^{\circ} \mathrm{C}\right)$ & & Average linear thermal expansion coefficient $\left(\times 10^{-6 \circ} \mathrm{C}^{-1}\right)$ & Fe-30Cr-3.5C \\
\hline Average $\alpha 1\left(10^{-6} \mathrm{~K}^{-1}\right)$ & Fe-30Cr-2.5C & Fe-30Cr-3.0C & $\mathbf{1 5 . 7}$ \\
$T$ range for $\alpha 1$ & $\mathbf{1 7 . 8}$ & $\mathbf{1 5 . 2}$ & $200-800^{\circ} \mathrm{C}$ \\
Contraction $T$ range & $230-725^{\circ} \mathrm{C}$ & $700-800^{\circ} \mathrm{C}$ & $780-821^{\circ} \mathrm{C}$ \\
Average $\alpha 2\left(10^{-6} \mathrm{~K}^{-1}\right)$ & $808-886^{\circ} \mathrm{C}$ & $\mathbf{7 9 3} 7^{\circ} \mathrm{C}$ & $\mathbf{1 3 . 9}$ \\
$T$ range for $\alpha 2$ & $\mathbf{2 4 . 5}$ & $\mathbf{2 1 . 5}$ & $820-1185^{\circ} \mathrm{C}$ \\
$\varepsilon_{1200 \%}$ end heating & $870-995^{\circ} \mathrm{C}$ & $1.570-1170^{\circ} \mathrm{C}$ & 1.422 \\
$\varepsilon_{1200 \%}$ start cooling & 1.996 & 1.537 & 1.366 \\
Total $\Delta \varepsilon_{1200 \%}$ & 1.720 & -0.041 & -0.056 \\
Total $\Delta \varepsilon_{100 \%}$ & -0.276 & +0.166 & -0.223 \\
\hline
\end{tabular}

alloys. Unsurprisingly too, the obtained hardness are very high and increase with the carbon content in the three systems, showing that such alloys are very hard and suitable for wear-resistance applications (especially the cobalt alloys and the iron alloys with their $600 \mathrm{Hv}$ and more). This can be easily explained by the great hardness of the present carbides: $1336 \mathrm{Hv}_{50 \mathrm{~g}}$ for $\mathrm{Cr}_{7} \mathrm{C}_{3}$ and $1350 \mathrm{Hv}_{50 \mathrm{~g}}$ for $\mathrm{Cr}_{3} \mathrm{C}_{2}$ [24].

If the temperature of these alloys increases, these ones logically know thermal expansion. Concerning the nickel alloys, this expansion is globally linear, at least until reaching a very high level of temperature $\left(1200^{\circ} \mathrm{C}\right.$ for the Ni-30Cr2.5C and $\mathrm{Ni}-30 \mathrm{Cr}-3.0 \mathrm{C}$ alloys, $900^{\circ} \mathrm{C}$ for the Ni-30Cr-3.5C alloy). This is not surprising since the matrix remains FCC over the whole temperature range, as verified with ThermoCalc calculations (which also confirms the possibility to get both $\mathrm{Cr}_{7} \mathrm{C}_{3}$ and $\mathrm{Cr}_{3} \mathrm{C}_{2}$ carbides for the three alloys). The heating parts of the dilatometry curves of the cobalt alloys are also globally linear, despite the theoretical change of matrix from HCP to FCC as predicted by Thermo-Calc near $500^{\circ} \mathrm{C}$. It is true that the matrix was not initially wholly $\mathrm{HCP}$ as shown by the XRD patterns performed on the as-cast cobalt alloys. However, one can think that the alloy has become wholly austenitic at the end of heating, without accompanying dilatometry phenomenon. The new appearance of a new HCP part of matrix during cooling seems being revealed by small discontinuities in the dilatometry curve at $700^{\circ} \mathrm{C}$ and in two cases (Co-30Cr-3.0C and $\mathrm{Co}-30 \mathrm{Cr}-3.5 \mathrm{C})$ at $500^{\circ} \mathrm{C}$, which is the temperature of the FCC $\rightarrow$ HCP change according to Thermo-Calc calculations. The iron alloys also know a linear thermal expansion at heating, but which is linear on two parts. The low-temperature one corresponds to a ferritic matric (revealed by the XRD patterns) and the hightemperature one corresponds to an austenitic matrix. This allotropic change, occurring over about $800-900^{\circ} \mathrm{C}$, is also predicted by Thermo-Calc for these three alloys. One can notice that the dilatometry runs show that the temperature range of $\alpha \rightarrow \gamma$ transformation slightly decreases when the carbon content increases, from about $810-890^{\circ} \mathrm{C}$ for the $\mathrm{Fe}-$ $30 \mathrm{Cr}-2.5 \mathrm{C}$ alloy to $780-820^{\circ} \mathrm{C}$ for the $\mathrm{Fe}-30 \mathrm{Cr}-3.5 \mathrm{C}$ alloy, which is slightly lower than for pure iron for which this transformation occurs near $910^{\circ} \mathrm{C}$ with the same contraction consequence.

Almost all the alloys have also encountered, either already before the end of heating or at least during the whole isothermal stage, a contraction which often results in a residual negative deformation after return to $100^{\circ} \mathrm{C}$ in our case. Such curious behaviour was previously encountered, and explained, for ( $\mathrm{Ni}, \mathrm{Co}$, or Fe)-30Cr-0.8C alloys [25]: the difference of thermal expansion coefficient between the matrix (e.g., $18-20 \times 10^{-60} \mathrm{C}^{-1}$ for a Ni-30Cr binary alloy) and the chromium carbides (about $10 \times 10^{-6 \circ} \mathrm{C}^{-1}$ ) leads to an increasing tensile elastic deformation of the carbides due to matrix expansion, accompanied by an increased compression stress applied by carbides to the matrix; when temperature is high enough to weaken the matrix, this one can be visco-plastically deformed in compression under the action of the carbides which reduces their accumulated tensile stresses. Such phenomena may appear if carbides are sufficiently present 
in the metallic alloys, but it can be reduced, and even eliminated, by fragmenting carbides by applying an adequate heat treatment if the carbides are not too coarse and not too numerous [26].

This contraction affects the Ni-30Cr-2.5C and Ni-30Cr3.0C alloys only during the isothermal stage, and during this hour at $1200^{\circ} \mathrm{C}$, the deformation in compression is greater for a higher carbon content, that is, for a higher carbides fraction. Due to a higher carbide fraction, the contraction begins before the end of the heating for the C-richest nickel alloy, and goes on, with a higher rate than for the two other alloys, during the isothermal stage. The same phenomenon affects the cobalt alloys, but with different forms. The Co-30Cr$2.5 \mathrm{C}$ alloy globally behaves like the nickel alloy containing the same carbon. Because of their higher carbide fractions, the linear parts of the thermal expansion of the $\mathrm{Co}-30 \mathrm{Cr}$ 3.0C and Co-30Cr-3.5C alloys display rates of deformation versus temperature which are lower. But when temperature is high enough, it seems that the compressed matrix becomes more $(\mathrm{Co}-30 \mathrm{Cr}-3.0 \mathrm{C})$ or less $(\mathrm{Co}-30 \mathrm{Cr}-3.5 \mathrm{C})$ free from the grip of carbides, but these ones finish to compress matrix at least during the isothermal stage. At the end of this one, just before cooling, the total deformation of the alloy is anyway lower for the alloys containing more carbides. Concerning the iron alloys, similar observations can be made, and the deformation at the end of heating as well as the deformation at the end of isothermal stage, is also lower if the carbon content or carbide fraction is higher in the alloy.

Thus there are significant consequences for the dimensional evolution of carbides-rich alloys in temperature cycling conditions. To avoid such effects and hysteresis of deformation between heating and cooling, it may be first possible to fragment carbides by applying a specific heat treatment, as already successfully obtained for alloys less rich in carbon. Another possible mean is to reinforce the matrix, for example, by solid solution strengthening, to allow it to deform reversibly by remaining in the elastic deformation domain and then avoiding visco-plastic deformation.

\section{Conclusions}

The alloys of this study, which are for most of them simplified versions of real alloys used to resist wear, for example, as coatings deposited on mechanical pieces, present logically high levels of hardness-especially when based on cobalt or iron-and also particular thermal expansion behaviours. In service, if frictions lead to very high temperatures, such behaviours may induce small but real deformation of these pieces, a lack of geometrical stability which can become a problem. But some means for diminishing this effect potentially may exist, by structural hardening allowing matrix to better resist visco-plastic deformation and then recovering a reversible character of deformation.

\section{Acknowledgments}

The authors wish to thank E. Souaillat, O. Hestin, M. Ba, and A. Dia, master students, for their contributions, as well as T. Schweitzer for his technical assistance.

\section{References}

[1] E. F. Bradley, Superalloys: A Technical Guide, ASM International, Materials Park, Ohio, USA, 1988.

[2] C. T. Sims and W. C. Hagel, The Superalloys, John Wiley \& Sons, New York, NY, USA, 1972.

[3] P. Kofstad, High Temperature Corrosion, Elsevier Applied Science, London, UK, 1988.

[4] D. Young, High Temperature Oxidation and Corrosion of Metals, Elsevier, Amsterdam, The Netherlands, 2008.

[5] A. Klimpel, L. A. Dobrzański, A. Lisiecki, and D. Janicki, "The study of properties of $\mathrm{Ni}-\mathrm{W}_{2} \mathrm{C}$ and $\mathrm{Co}-\mathrm{W}_{2} \mathrm{C}$ powders thermal sprayed deposits," Journal of Materials Processing Technology, vol. 164-165, pp. 1068-1073, 2005.

[6] Z.-T. Wang and H.-H. Chen, "Microstructure and friction and wear behavior of induction clad Ni-based composite coating reinforced with micro- and nano-WC particulates," Mocaxue Xuebao/Tribology, vol. 25, no. 3, pp. 203-206, 2005.

[7] H. Han, S. Baba, H. Kitagawa et al., "Plasma-carburization of nickel-based self-fluxing alloy," Vacuum, vol. 78, no. 1, pp. 2732, 2005.

[8] D. Zhang and X. Zhang, "Laser cladding of stainless steel with $\mathrm{Ni}-\mathrm{Cr}_{3} \mathrm{C}_{2}$ and $\mathrm{Ni}$-WC for improving erosive-corrosive wear performance," Surface and Coatings Technology, vol. 190, no. 2-3, pp. 212-217, 2005.

[9] P. Berthod, J. L. Bernard, and C. Liébaut, Cobalt Alloy and Fabrication of Articles from the Alloy, Patent WO99/16919.

[10] B. Roebuck and E. A. Almond, "Deformation and fracture processes and the physical metallurgy of WC-Co hardmetals," International Materials Reviews, vol. 33, no. 2, pp. 90-110, 1988.

[11] H. E. N. Stone, "Hardness, oxidation and constitution in chromium-iron alloys," Journal of Materials Science, vol. 14, no. 12, pp. 2787-2790, 1979.

[12] B. V. Cockeram, "Some observations of the influence of $\delta$-ferrite content on the hardness, galling resistance, and fracture toughness of selected commercially available iron-based hardfacing alloys," Metallurgical and Materials Transactions A, vol. 33, no. 11, pp. 3403-3419, 2002.

[13] T. B. Shafffer, Handbooks of High-Temperature Materials No.1. Materials Index, Plenum Press, New York, NY, USA, 1964.

[14] Thermo-Calc version N: "Foundation for Computational Thermodynamics" Stockholm, Sweden, Copyright (1993, 2000).

[15] J. O. Andersson, "Thermodynamic properties of Cr-C," Calphad, vol. 11, no. 3, pp. 271-276, 1987.

[16] A. Gabriel, C. Chatillon, and I. Ansara, "Thermochemical and phase diagram analysis of the Ni-C, Co-C, and $\mathrm{Co}-\mathrm{Ni}-\mathrm{C}$ systems," High Temperature Science, vol. 25, no. 1, pp. 17-54, 1988.

[17] A. Fernández Guillermet, "Critical evaluation of the thermodynamic properties of cobalt," International Journal of Thermophysics, vol. 8, no. 4, pp. 481-510, 1987.

[18] A. F. Guillermet, "Thermodynamic analysis of the Co-Al-C and Ni-Al-C systems," Zeitschrift für Metallkunde, vol. 78, no. 10, pp. 700-709, 1987.

[19] A. F. Guillermet, "Thermodynamic properties of the ironcobalt-carbon system," Zeitschrift für Metallkunde, vol. 79, no. 5, pp. 317-329, 1988.

[20] A. Fernandez Guillermet and P. Gustafson, "Assessment of the thermodynamic properties and the $(\mathrm{p}, \mathrm{T})$ phase diagram of iron," High Temperatures—High Pressures, vol. 16, no. 6, pp. 591-610, 1984. 
[21] J. O. Andersson and B. Sundman, "Thermodynamic properties of the CrFe system," Calphad, vol. 11, no. 1, pp. 83-92, 1987.

[22] P. Gustafson, "A thermodynamic evaluation of the C-Fe system," Scandinavian Journal of Metallurgy, vol. 14, no. 5, pp. 259-267, 1985.

[23] J.-O. Andersson, "A thermodynamic evaluation of the Fe-Cr-C system," Metallurgical Transactions A, vol. 19, no. 3, pp. 627636, 1988.

[24] G. V. Samsonov, Handbooks of High-Temperature Materials No. 2. Properties Index, Plenum Press, New York, NY, USA, 1964.

[25] P. Berthod, "Influence of carbides and of the dendritic orientation on the thermal expansion of Ni-base, Co-base and Fe-base simple cast alloys," International Journal of Materials Research, vol. 99, no. 3, pp. 265-272, 2008.

[26] P. Berthod, C. Heil, and L. Aranda, "Influence of the morphologic evolution of the eutectic carbides at high temperature on the thermal expansion behavior of refractory cast alloys," Journal of Alloys and Compounds, vol. 504, no. 1, pp. 243-250, 2010. 

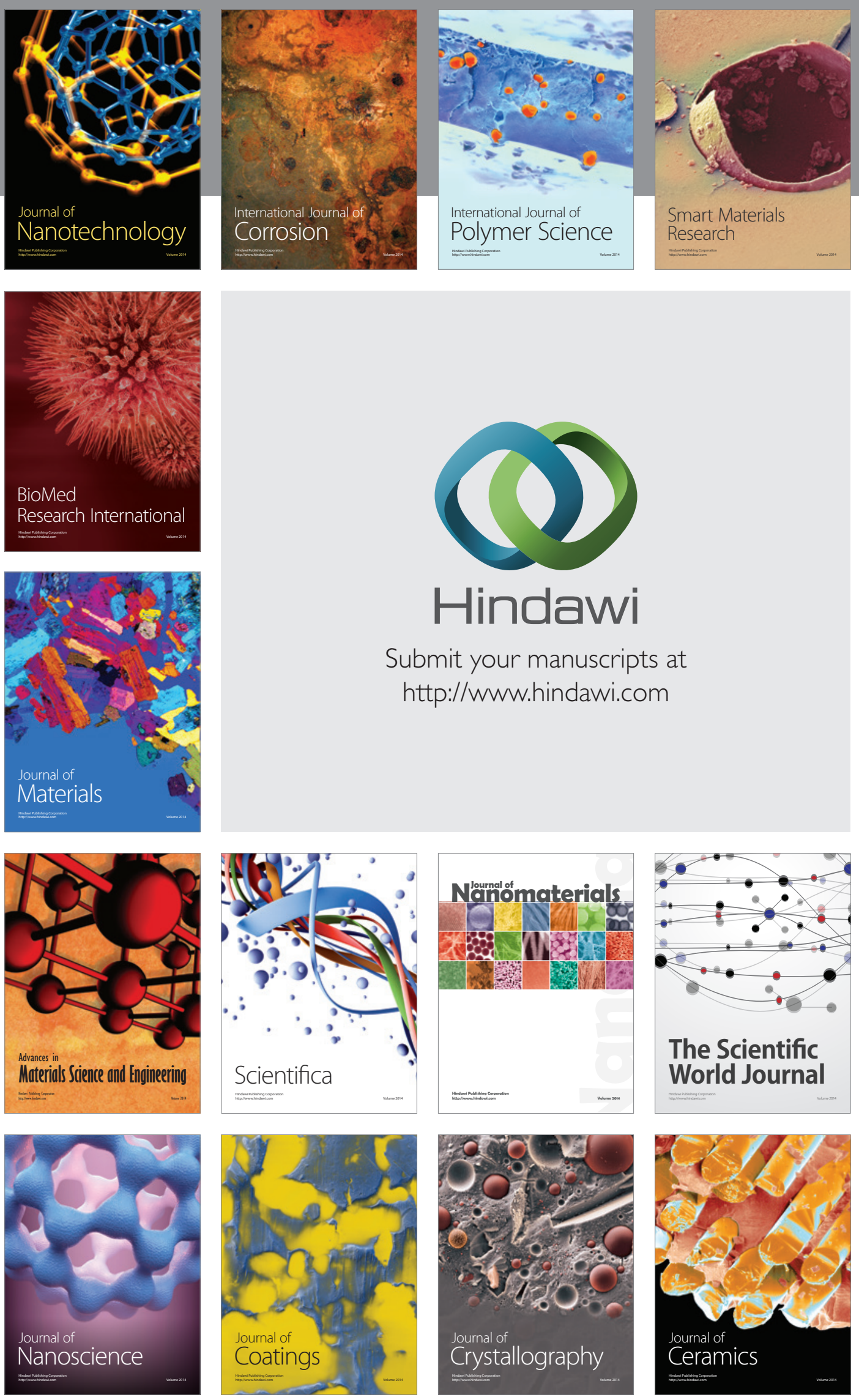

The Scientific World Journal

Submit your manuscripts at

http://www.hindawi.com

\section{World Journal}

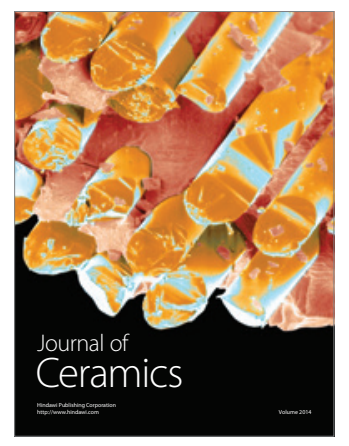

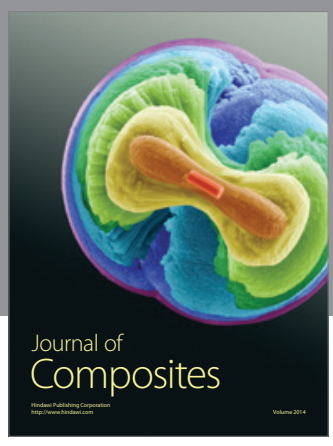
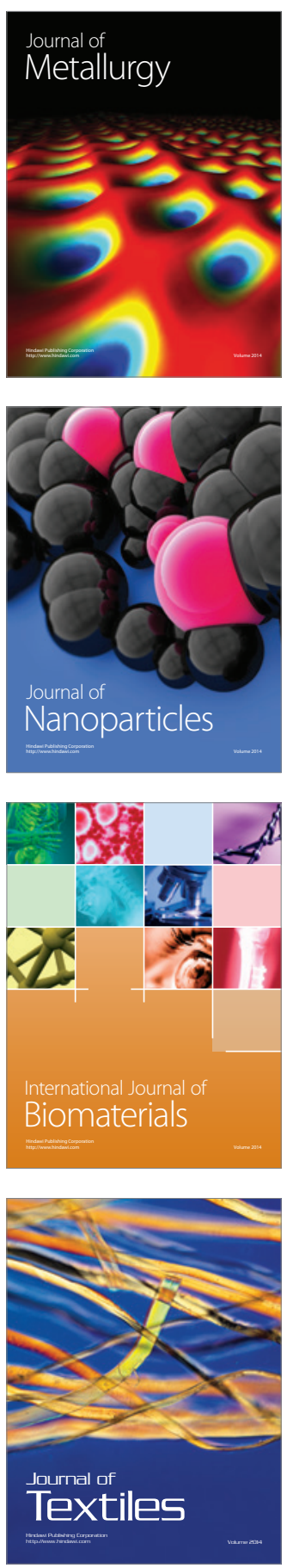